\title{
R.F. PLANAR MAGNETRON SPUTTERED ZnO FILMS I: STRUCTURAL PROPERTIES
}

F. C. M. VAN DE POL* F. R. BLOM $\dagger$ AND TH. J. A. POPMA

University of Twente, Department of Electrical Engineering, P.O. Box 217, 7500 AE Enschede (The Netherlands)

(Received October 23, 1990; accepted February 12, 1991)

The structural properties of r.f. planar magnetron sputtered $\mathrm{ZnO}$ films are studied as a function of deposition parameters: substrate type, substrate temperature, sputter gas pressure, growth rate and sputtering power.

These films are applied as piezoelectric transducers in micromechanical sensors and actuators. The electric properties, and consequently the piezoelectric behaviour, depend strongly on the structural properties of the layers.

All films are polycrystalline. The individual grains are highly oriented with their crystallographic $c$ axis perpendicular to the substrate. Crystalline substrates such as silicon or $\mathrm{SiO}_{2}$ induce a growth of small grains, a few hundredths of a micron wide and long. Amorphous substrates such as metals or amorphous $\mathrm{SiO}_{2}$ induce a growth of broad columnar grains extending through the film thickness and a few tenths of a micron wide. Trends in density and grain size are in agreement with Thornton's structure zone model.

\section{INTRODUCTION}

At our university, within the Transducers and Materials Science research group, sputtered $\mathrm{ZnO}$ films have been studied since 1981. These films are applied as optical waveguides ${ }^{1}$ or as electromechanical transducers ${ }^{2-4}$.

Most of the reported research on piezoelectric $\mathrm{ZnO}$ films deals with acoustical applications at high (megahertz) frequencies, where losses due to direct currents do not play a role. Our work is concerned with $\mathrm{ZnO}$ films sputtered on silicon and related substrates, and their application as piezoelectric transducers in micromechanical sensors and actuators at low frequencies.

\subsection{Sputtered thin film $\mathrm{ZnO}$}

Nowadays a wide variety of deposition techniques for $\mathrm{ZnO}$ is described in literature ${ }^{5}$, but by general consent sputtering yields the best piezoelectric ${ }^{6}$ and optic $^{1}$ layers because highly oriented and dense layers can be obtained. Sputtered $\mathrm{ZnO}$ films are regarded as the most useful piezoelectric thin film material ${ }^{7}$.

$\mathrm{ZnO}$ belongs to the hexagonal wurtzite crystal type, having $6 \mathrm{~mm}$ symmetry. Sputtered $\mathrm{ZnO}$ films are polycrystalline, the individual crystals growing preferentially with their crystallographic $c$ axis perpendicular to the substrate.

\footnotetext{
* Present address: Schlumberger Industries SMR Montrouge, France.

† Present address: Oce Nederland B.V. Venlo, The Netherlands.
} 


\subsection{Problem and outline of research}

It was concluded that the piezoelectric behaviour of the $\mathrm{ZnO}$ films, applied in micromechanical devices developed by our group, was much worse than had been expected $^{2-4}$. Suggested possible causes were (i) lower piezoelectric coefficients for the films than the bulk values, (ii) losses due to direct currents and (iii) structural deviations.

The films are sputtered on substrates of silicon, silicon oxide (crystalline and amorphous), metal (aluminium, silver and gold) or quartz, from a zinc target in a pure oxygen atmosphere by a planar r.f. magnetron sputter unit. The most important deposition parameters are substrate type, substrate temperature, oxygen pressure, growth rate and sputtering power.

We studied the structural, electric and piezoelectric properties of these films and their relations with the deposition parameters. Electric properties are discussed in Part II. A study on the piezoelectric behaviour has been reported elsewhere ${ }^{8}$.

In this paper (Part I) we deal with structure and chemical composition. Papers most related to this work are by Horsthuis ${ }^{1}$, Sen et al. ${ }^{9}$ and Krupanidhi and Sayer ${ }^{10}$. Section 2 deals with growth models from literature. In Section 3, experiments concerning X-ray diffraction (XRD), scanning electron microscopy (SEM), surface profiling and Auger electron spectroscopy (AES) are described. Results are given and discussed in Section 4, while conclusions concerning the structural and chemical film properties are presented in Section 5.

\section{GROWTH MODELS}

\subsection{Film growth ${ }^{11,12}$}

In general, two stages are distinguished in thin film growth; initial growth (nucleation and coalescence) and actual growth. During initial growth, chemical and physical properties of the substrate, and interaction between substrate and particles arriving there, play an important role. After an initial layer covering the substrate has formed, actual growth begins, during which interaction only occurs between particles of the film material.

Important parameters are the energy of the particles arriving at the substratefilm surface, energy absorption at the time of collision, and chemical and physical interaction between adatoms and the substrate-film surface as well as temperature. These parameters determine, to a great extent, the morphology (overall shape of the film and the geometry of crystallites or amorphous structures inside the film) and texture (orientation of the crystallites).

\subsection{Growth models}

Movchan and Demchishin ${ }^{13}$ studied evaporated layers of metals or oxides. They finished up with a model having three zones. Thornton ${ }^{14}$ extended this model to a model for sputtered layers of metals with a fourth zone and an additional axis: the argon sputter gas pressure (Fig. 1). In zone 1 (porous with tapered crystallites), porous layers with rough surfaces are formed owing to low adatom mobility (slow surface diffusion) and the "shadow effect". In zone 2 (dense; columnar grains from top to bottom), adatom mobility is high enough to overcome the shadow effect and 


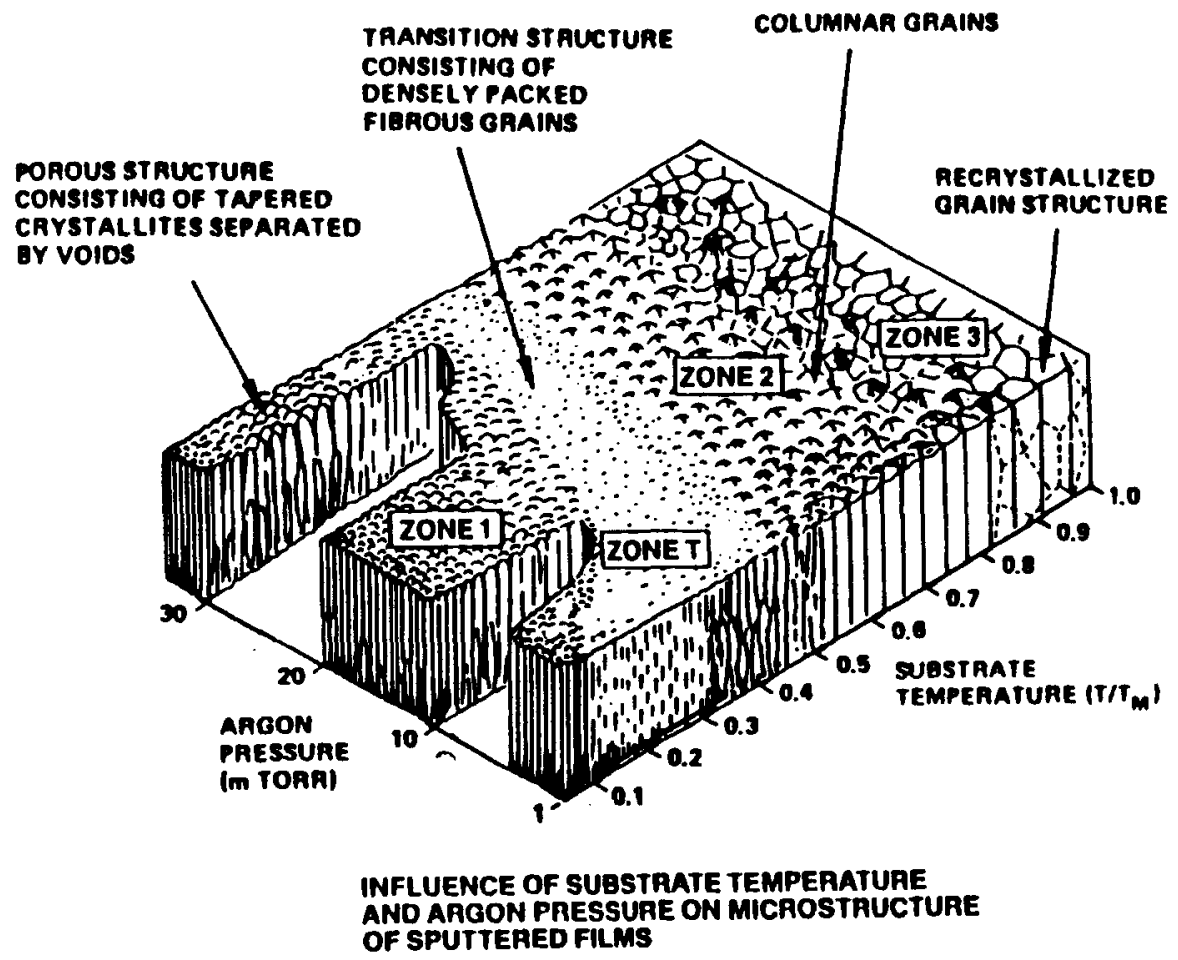

Fig. 1. Structure zone model for sputtered films of metals ${ }^{14}$.

growth is controlled by surface diffusion, resulting in more dense layers with small columnar grains. In zone 3 (recrystallized grains), because of bulk diffusion smaller grains coalesce to form larger, not necessarily columnar, grains. There is a fourth (transition) zone $\mathrm{T}$ (dense; fibre-like grains) in which grain outlines are difficult to identify.

Because of collisions with argon atoms, the energy of the particles arriving at the substrate-film surface decreases with increasing argon pressure, leaving less energy for surface diffusion. In addition, at high pressures, adsorbed argon limits adatom mobility. Therefore the transition temperatures between zones $1, T$ and 2 increase with argon pressure. The transition temperature between zone 2 and 3 is independent of argon pressure, since this transition is determined by bulk diffusion. Structure zone models have been reviewed by Thornton ${ }^{15}$.

\subsection{Oriented growth}

Several mechanisms can cause growth of oriented layers. If the lattice constants of substrate and film material approximately match each other, epitaxial growth can occur. However, even if the lattice constants do not match, oriented growth is often observed. A general texture model and conditions for non-epitaxial oriented growth are given by Bauer ${ }^{16,17}$.

An increase in orientation during actual growth is possible according to the 
model of Van der Drift ${ }^{18}$. This model, often referred to as "survival of the fastest", is based on different growth rates of the crystal planes: starting from random crystal orientation in the initial layer, crystals with the fastest growing crystal plane parallel to the substrate "survive" at the cost of the others. This model implies a related increase in crystal orientation and grain size with film thickness.

In films that are well oriented from the very first stage, the "survival of the fastest" model cannot explain an increase in grain size with film thickness (taperwise grain growth). Lodder et al. ${ }^{19}$ suggest a thermodynamically driven coalescence of crystallites (grain boundary movement) during film growth, as an explanation for this frequently observed phenomenon.

\section{EXPERIMENTS}

\subsection{Samples}

As mentioned previously, the films are r.f. planar magnetron sputtered from a zinc target in a pure oxygen atmosphere. The sputter equipment is described in detail by Horsthuis ${ }^{1}$, who determined the optimum deposition parameters to obtain dense, smooth, highly oriented layers with minimum optical attenuation.

From now on, the following set of deposition parameters is referred to as "sconditions":

substrate temperature $T_{s}=400-450^{\circ} \mathrm{C}$

r.f. forward sputter power $P=1800 \mathrm{~W}$

oxygen pressure $p_{\mathrm{O}_{2}}=0.86 \mathrm{~Pa}$

target-substrate distance tsd $=45 \mathrm{~mm}$

$\mathrm{ZnO}$ films deposited under these s-conditions are referred to as " $\mathrm{s}-\mathrm{ZnO}$ ".

A number of layers were deposited on silicon wafers under s-conditions with one parameter varied. Also some s-ZnO films were grown on chemically vapour deposited $\mathrm{SiO}_{2}$ and metal substrates (aluminium, silver and gold). The growth rate is measured in situ by a laser beam thickness monitor using interference.

\subsection{X-ray diffraction and scanning electron microscopy}

Crystallographic ordering, crystal orientation (texture) and grain size were studied by means of XRD. $2 \vartheta$ scans and rocking curves around the (002) peak were produced using a Siemens system 1.4 Omega number 4 diffractometer, with a copper or cobalt source. In order to determine more precisely the width of the peaks, some extra-slow $\left(7.5^{\circ} \mathrm{h}^{-1}\right) 29$ scans were recorded using a Philips PW1710 diffractometer, with a copper source.

SEM micrographs of cross-sections and surfaces of the films were recorded using an ISI SS40 electron microscope, providing information on grain geometries, density and surface roughness (morphology).

The films are cleaved at room temperature ("RT cleaving") or at $75 \mathrm{~K}$, submerged in liquid nitrogen ("LN cleaving"). Cleaving is relatively simple since the substrates are brittle silicon wafers. In order to minimize charge build-up during SEM, some experiments were carried out involving evaporation of carbon or gold. 
SEM micrographs of freshly broken layers, and slightly etched (in $\mathrm{H}_{3} \mathrm{PO}_{4}-\mathrm{HAc}-\mathrm{H}_{2} \mathrm{O}$ or photoanodically in $\mathrm{K}_{2} \mathrm{SO}_{4}-\mathrm{H}_{2} \mathrm{O}$ ) cross-sections and surfaces, were recorded.

\subsection{Surface profiling and Auger electron spectroscopy}

In order to determine film roughness, surface profiles were scanned for asdeposited layers and slightly etched films, using a DEKTAK 3030 surface profiler.

Chemical composition was studied by means of AES using a Perkin-Elmer PHI 600 Auger spectroscope. Surveys of the surface and depth profiles of zinc and oxygen were recorded for some layers.

\section{RESULTS AND DISCUSSION}

\subsection{Growth rate}

Deposition parameters, substrate type and thickness of the films studied are summarized in Table I. As shown in Fig. 2, the growth rate increases linearly with sputter power $P$, and is approximately independent of substrate temperature $T_{\mathrm{s}}$, and decreases with increasing oxygen pressure $p_{\mathrm{O}_{2}}$.

We can conclude that the mean free path and the rate of particles arriving at the substrate determine the growth rate (rate determined by diffusion).

\subsection{9 scans and rocking curves}

29 scans and rocking curves around the (002) peak, recorded from samples K11-K25, all look alike. Figure 3 shows typical results. Apart from two peaks arising from the silicon substrate, only the (002) and (004) reflections appear in the diffractograms, indicating oriented growth with the crystallographic $c$ axis perpendicular to the substrate surface. Table II summarizes measured values of 29 for the $(002)$ and (004) reflections and the full width at half-maximum (FWHM) of the peaks. The accuracy of the measured angles is approximately $1^{\circ}$. Measured $29(002)$ and $2 \gamma(004)$ values for all layers coincide with bulk values ${ }^{20}$ within $1^{\circ}$. The width of the rocking curves is a few degrees for all measured samples, indicating a highly oriented $c$ axis. These results agree with Bauer's texture model ${ }^{16}$, which predicts [001]oriented initial growth for hexagonal crystals.

Some extra-slow $\left(7.5^{\circ} \mathrm{h}^{-1}\right)$ XRD curves were recorded for samples K16, K19 and $\mathrm{K} 20$. The grain size $D_{\perp}$, perpendicular to the substrate, as calculated from ${ }^{21}$

$$
D_{\perp}=\frac{\lambda}{B \cos \vartheta}
$$

with $\lambda$ the $X$-ray wavelength, $B$ the integral peak width, corrected for instrumental broadening $B_{1}$ and $\vartheta$ the reflection angle, is given in Table III. Absolute values of $D_{1}$, which actually represents the longitudinal coherence length, are inaccurate since the instrumental broadening $B_{1}$ is roughly estimated and of the same order of magnitude as the integral peak width $B$. However, it is clear that $D_{\perp}$ increases with substrate temperature.

We can conclude that all films studied with XRD are crystalline $\mathrm{ZnO}$, with the $c$ axis highly oriented within a few degrees perpendicular to the substrate surface, in 
TABLE I

DEPOSITION PARAMETERS, SUBSTRATE TYPE AND THICKNESS OF THE FILMS

\begin{tabular}{|c|c|c|c|c|c|}
\hline $\begin{array}{l}\text { Wafer } \\
\text { number }\end{array}$ & $\begin{array}{l}\text { Substrate } \\
\text { type }\end{array}$ & $\begin{array}{l}\text { Oxygen } \\
\text { pressure } \\
\text { (Pa) }\end{array}$ & $\begin{array}{l}\text { Substrate } \\
\text { temperature } \\
\left({ }^{\circ} \mathrm{C}\right)\end{array}$ & $\begin{array}{l}\text { Sputter } \\
\text { power } \\
\text { (W) }\end{array}$ & $\begin{array}{l}\text { Thickness } \\
(\mu \mathrm{m})\end{array}$ \\
\hline K15 & $\mathrm{Si}(100)$ & 0.53 & $400-450$ & 1800 & 1.0 \\
\hline K11 & & 0.86 & & & 1.0 \\
\hline $\mathrm{K} 12$ & & 1.1 & & & 1.1 \\
\hline K13 & & 8.7 & & & 1.1 \\
\hline K 14 & & 23 & & & 1.1 \\
\hline K16 & $\operatorname{Si}(100)$ & 0.86 & $40-100$ & 1800 & 1.0 \\
\hline K17 & & & $70-130$ & & 1.0 \\
\hline K18 & & & $170-245$ & & 1.0 \\
\hline K19 & & & $290-320$ & & 1.0 \\
\hline $\mathrm{K} 20$ & & & $490-530$ & & 1.0 \\
\hline K21 & $\mathrm{Si}(100)$ & 0.86 & $400-450$ & 800 & 0.9 \\
\hline K22 & & & & 1200 & 1.0 \\
\hline K23 & & & & 1400 & 1.0 \\
\hline K24 & & & & 1600 & 1.0 \\
\hline K22 & & & & 1900 & 1.0 \\
\hline F41 & $\operatorname{Si}(100)$ & 0.59 & $400-450$ & 1800 & 1.1 \\
\hline F43 & & 0.92 & & & 1.0 \\
\hline F42 & & 2.1 & & & 1.0 \\
\hline F45 & & 3.9 & & & 0.8 \\
\hline F44 & & 23 & & & 1.0 \\
\hline B65 & $\begin{array}{l}\text { Chemical } \\
\text { vapour } \\
\text { deposited } \\
\mathrm{SiO}_{2}\end{array}$ & 0.86 & $400-450$ & 1800 & 4.8 \\
\hline B77 & & & & & 4.0 \\
\hline X01 & $\mathrm{Si}(100)$ & 0.86 & $400-450$ & 1800 & 5 \\
\hline X02 & $\operatorname{Si}(100)$ & & & $1800 \rightarrow 400$ & 5 \\
\hline $\mathrm{X} 03$ & $\mathrm{Al}$ & 0.86 & $400-450$ & 1800 & 4 \\
\hline
\end{tabular}

Target-substrate distance, $45 \mathrm{~mm}$.

accordance with Bauer's general texture model ${ }^{16}$. The longitudinal coherence length for $1 \mu \mathrm{m} \mathrm{ZnO}$ on silicon, estimate as $0.01-0.05 \mu \mathrm{m}$, is much smaller than the film thickness and increases with the substrate temperature.

\subsection{Scanning electron micrographs}

SEM micrographs were recorded for all samples mentioned in Table I. Cleaving is induced from the back of the wafer, and thus it starts in the silicon. A large number of SEM micrographs were produced in order to establish which features observed were induced by cleaving. We found LN cleaving to yield the best results, provided that the silicon exhibits a smooth cleaved surface, since the fracture pattern of the silicon substrate tends to propagate into the film (Fig. 4).

Evaporation of carbon or sputtering of gold appears to be unnecessary; using a 


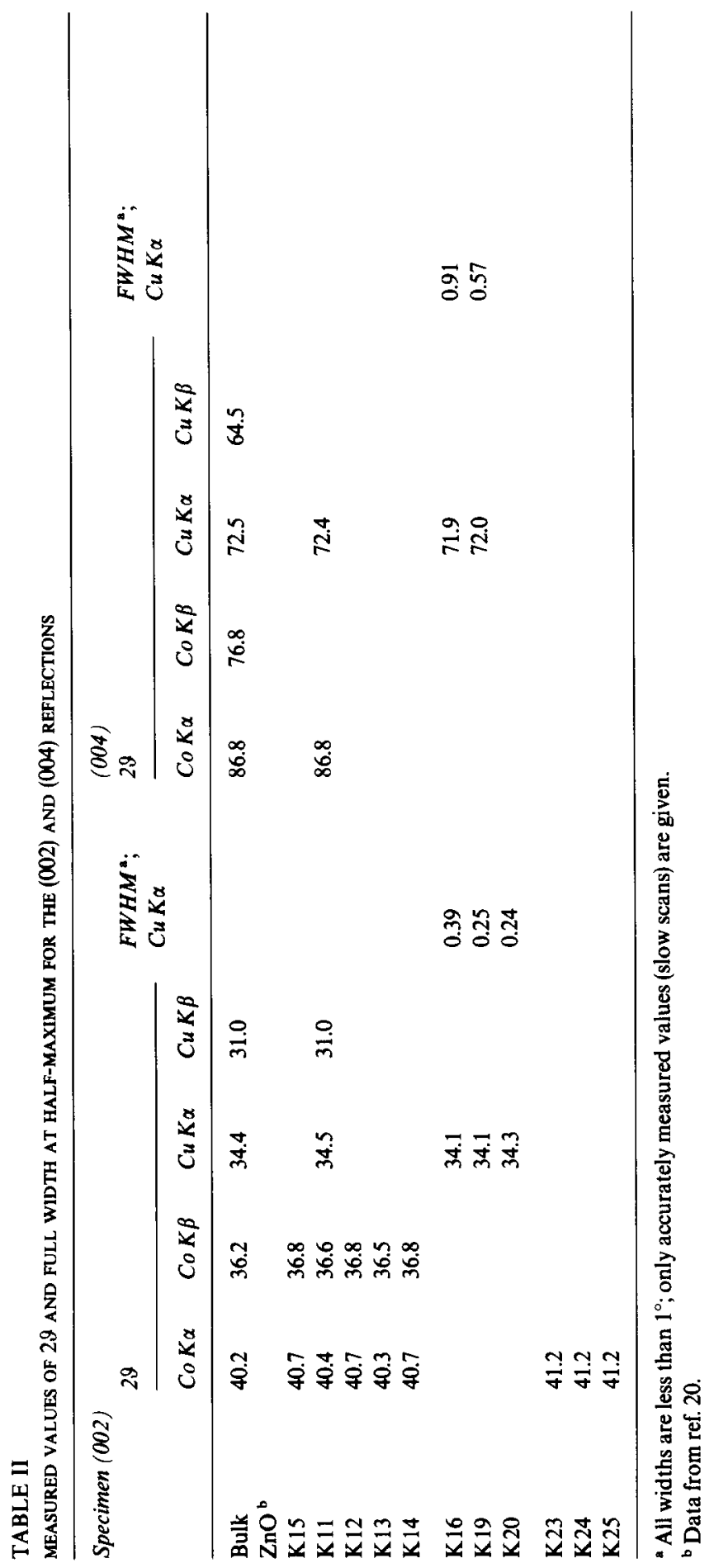



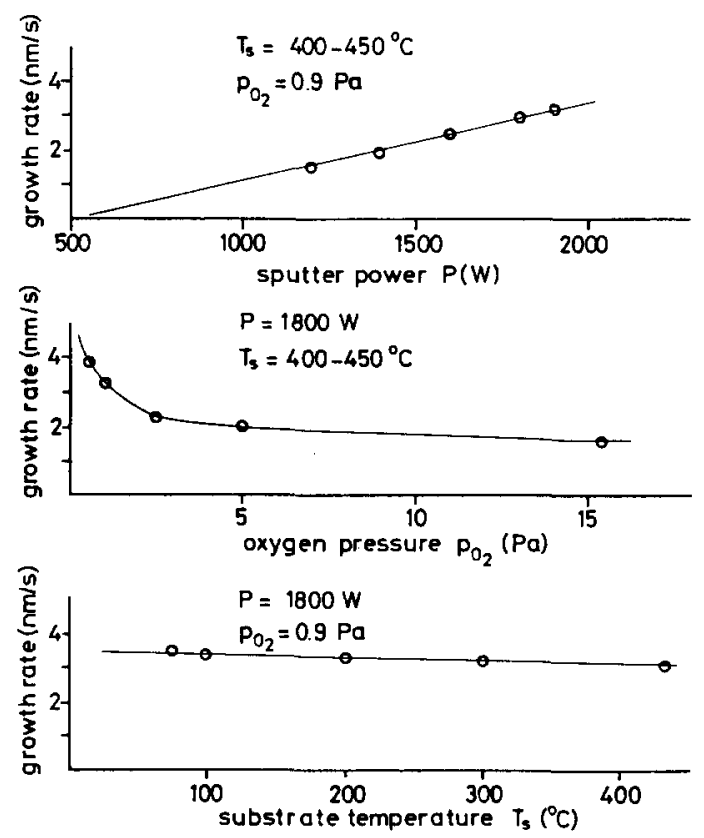

Fig. 2. Growth rate of $\mathrm{ZnO}$ films on $\mathrm{Si}(100)$ substrates as a function of deposition parameters: sputter power, oxygen pressure and substrate temperature.
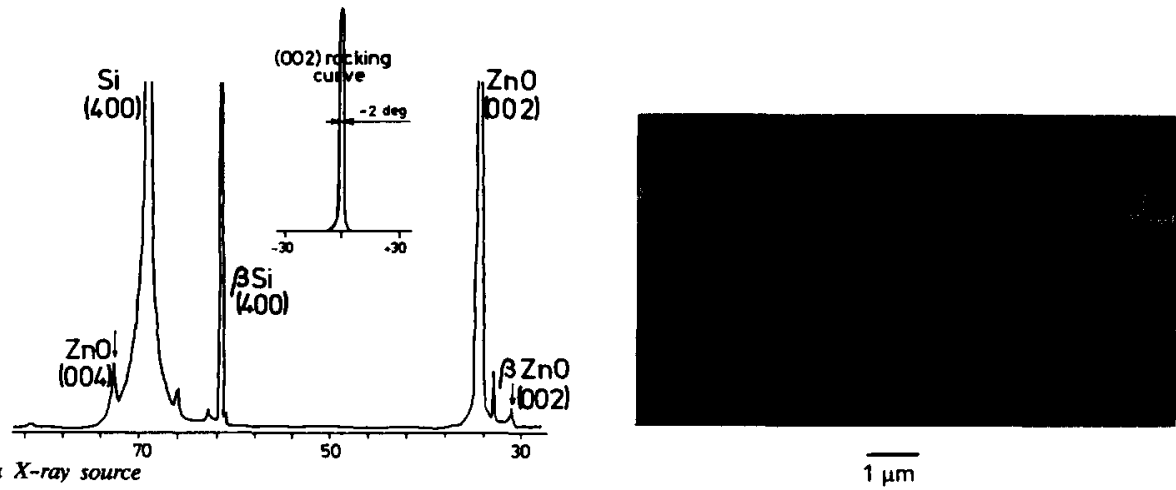

Fig. 3. Typical 29 scan and rocking curve around the $(002)$ peak for a $\mathrm{ZnO}$ film on an $\mathrm{Si}(100)$ substrate.

Fig. 4. SEM micrograph of a $1 \mu \mathrm{m} \mathrm{ZnO}$ film on an Si(100) substrate, showing the fracture pattern lines of the cleaved silicon substrate propagating into the $\mathrm{ZnO}$ film.

TABLE III

GRAIN SIZE $D_{\perp}$ AS CALCULATED FROM SLOWLY SCANNED PEAKS

\begin{tabular}{|c|c|c|c|c|c|c|c|}
\hline \multirow[t]{2}{*}{ Wafer } & \multirow[t]{2}{*}{$T_{s}\left({ }^{\circ} \mathrm{C}\right)$} & \multicolumn{2}{|c|}{$B_{\mathrm{i}}(\mathrm{deg})$} & \multicolumn{2}{|l|}{$B(\mathrm{deg})$} & \multicolumn{2}{|c|}{$D_{\perp}(\mathrm{nm})$} \\
\hline & & $(002)$ & (004) & $(002)$ & $(004)$ & $(002)$ & (004) \\
\hline $\mathrm{K} 16$ & $40-100$ & & & 0.52 & 0.92 & 18 & 12 \\
\hline K19 & $290-320$ & 0.14 & 0.18 & 0.27 & 0.74 & 34 & 14 \\
\hline K 20 & $490-530$ & & & 0.25 & & 37 & \\
\hline
\end{tabular}



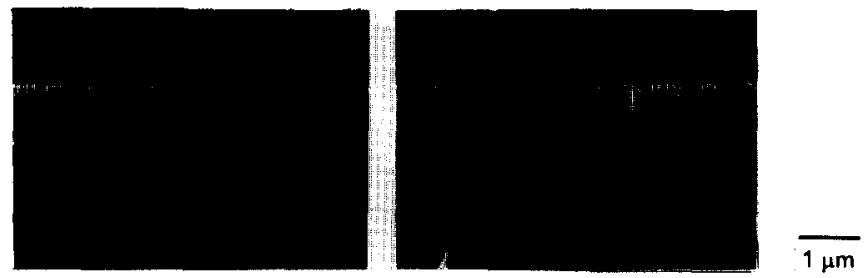

Fig. 5. Typical SEM micrographs of a $1 \mu \mathrm{m}$ thick $\mathrm{ZnO}$ film on an Si(100) substrate; the differences are induced by cleaving, since both micrographs represent the same layer.
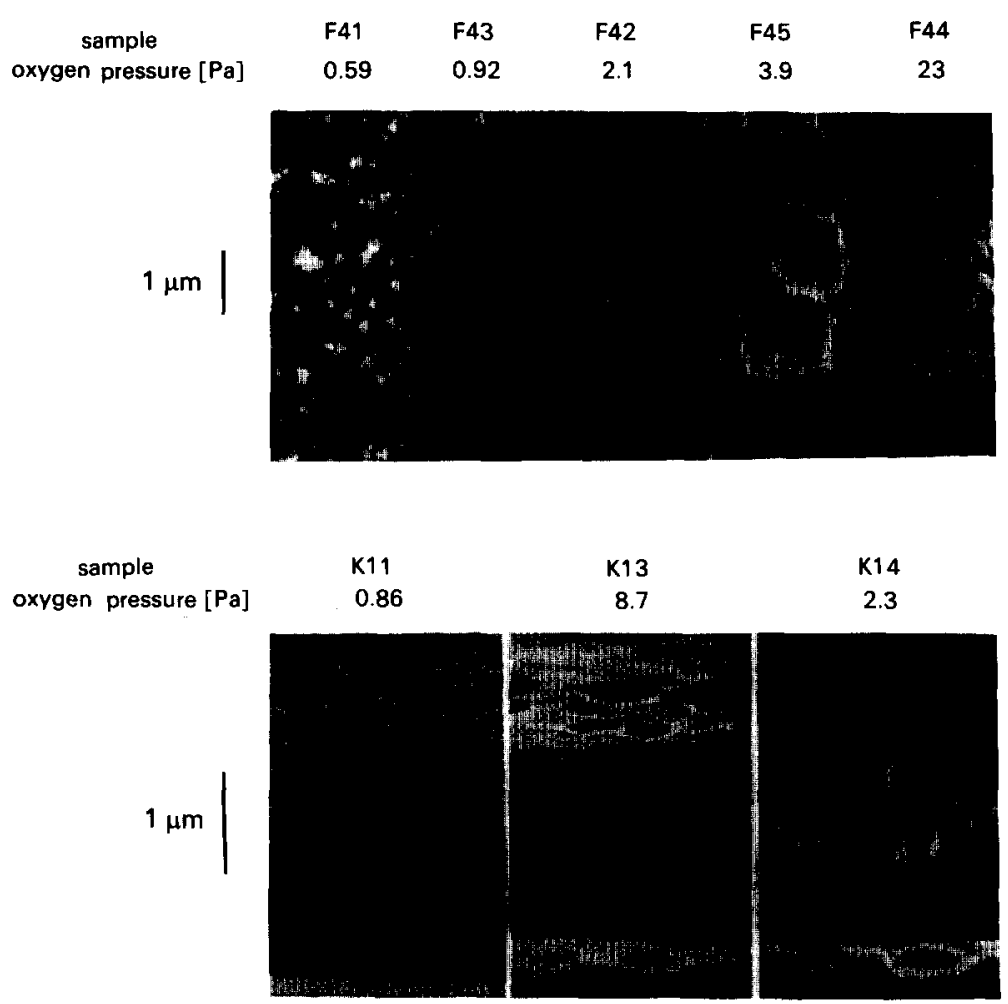

Fig. 6. SEM micrographs of $1 \mu \mathrm{m} \mathrm{ZnO}$ films sputtered on $\mathrm{Si}(100)$ substrates at various sputter gas $\left(\mathrm{O}_{2}\right)$ pressures (etched in $\mathrm{H}_{3} \mathrm{PO}_{4}-\mathrm{HAc}-\mathrm{H}_{2} \mathrm{O}$ ).

conducting paste to attach the samples to the SEM sample holder suffices to prevent charge build-up.

We found that all unetched cross-sections of samples $\mathrm{K} 11-\mathrm{K} 25$ (all $1 \mu \mathrm{m} \mathrm{ZnO}$ on silicon), as observed by SEM, are essentially the same and independent of deposition parameters. Figure 5 gives results for these layers, showing a fine pattern of vertical lines separated by a few hundredths of a micron, and very smooth surfaces. 


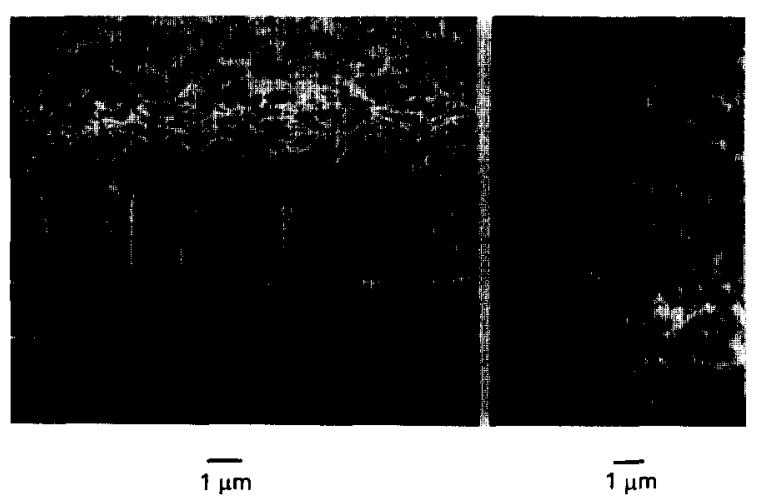

Fig. 7. SEM micrographs of $4-5 \mu \mathrm{m} \mathrm{ZnO}$ films sputtered on chemically vapour deposited $\mathrm{SiO}_{2}$ substrates (etched in $\mathrm{H}_{3} \mathrm{PO}_{4}-\mathrm{HAc}-\mathrm{H}_{2} \mathrm{O}$ ).

Samples K11, K13, K14, K16, K19, K20 and F41-F45 (all $1 \mu \mathrm{m}$ ZnO on silicon) were etched in an $\mathrm{H}_{3} \mathrm{PO}_{4}-\mathrm{HAc}-\mathrm{H}_{2} \mathrm{O}$ solution. We found that the fine line patterning in the cross-sections disappeared on etching. However, on the surface of the films, etch pits became visible (Fig. 6). For samples F43, F42 and F45, the etched surfaces look similar to etched (001) surfaces of single-crystal $\mathrm{ZnO}^{22}$, indicating dense "single-crystal-like" films. The etch pit density appears to decrease with increasing oxygen pressure. For the highest $p_{\mathrm{O}_{2}}=23 \mathrm{~Pa}$, etching is much faster than for other samples, indicating a more porous structure. The appearance of the etched surface is different for low oxygen pressures; it looks like the etched tops of a columnar structure.

Figure 7 shows SEM micrographs of samples B65 and B77 $(4.8 \mu \mathrm{m}$ and $4 \mu \mathrm{m}$ respectively $\mathrm{s}-\mathrm{ZnO}$ on chemically vapour deposited $\mathrm{SiO}_{2}$, etched in $\mathrm{H}_{3} \mathrm{PO}_{4}-\mathrm{HAc}-\mathrm{H}_{2} \mathrm{O}$ ). These samples exhibit structures with broad columns, $0.2-0.5 \mu \mathrm{m}$ wide, extending through the film thickness. The surfaces look like etched (001) surfaces of single-crystal $\mathrm{ZnO}^{22}$. The grain boundaries, being etched more readily, are visible.

Figure 8 shows an SEM micrograph ${ }^{23}$ of sample X03 $(4 \mu \mathrm{m} \mathrm{s}-\mathrm{ZnO}$ on aluminium, etched photoanodically in $\mathrm{K}_{2} \mathrm{SO}_{4}-\mathrm{H}_{2} \mathrm{O}$ ). Here also a columnar structure is clearly visible. Micrographs of layers grown on other metal films reveal that these layers have the same columnar structure.

Figure 9 shows SEM micrographs of samples X01 and X02. Sample X01 $(5 \mu \mathrm{m}$ $\mathrm{s}-\mathrm{ZnO}$ on silicon) exhibits a "toothed structure" on top of a layer with a fine vertical line pattern as observed earlier with $1 \mu \mathrm{m}$ thick layers. The surface appears to be relatively rough. However, sample $\mathrm{X} 02(5 \mu \mathrm{m} \mathrm{ZnO}$ on silicon, first $1.5 \mu \mathrm{m}$ sputtered at $1800 \mathrm{~W}$, then with the power decreased to $400 \mathrm{~W}$ ) exhibits no toothed structure; fine lines extend through the film thickness, and the surface is smooth. These results are in accordance with those of Horsthuis ${ }^{1}$, who found that optical "attenuation increased sharply for films thicker than $1 \mu \mathrm{m}$ ". These films were deposited at $1800 \mathrm{~W}$. However, if "only the initial layer was high-rate sputtered, while the bulk of the film was deposited at a much lower rate, i.e. applied RF power ... the attenuation was 


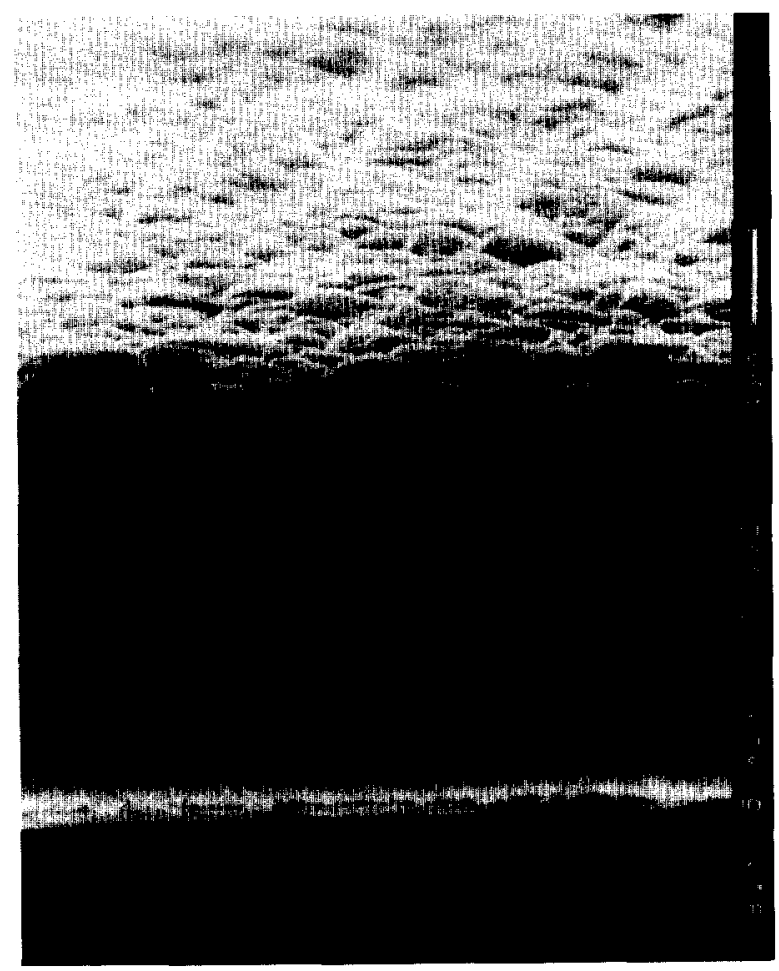

Fig. 8. SEM micrograph ${ }^{23}$ of a $4 \mu \mathrm{m} \mathrm{ZnO}$ film sputtered on an aluminium substrate (etched photoanodically in $\mathrm{K}_{2} \mathrm{SO}_{4}-\mathrm{H}_{2} \mathrm{O}$ ).

(a)

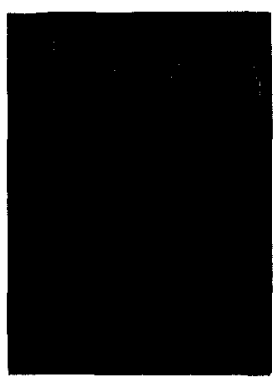

(b)

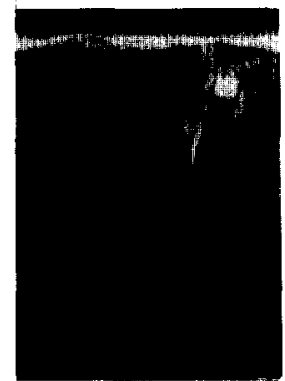

Fig. 9. SEM micrographs of $5 \mu \mathrm{m} \mathrm{ZnO} \mathrm{films} \mathrm{sputtered} \mathrm{on} \mathrm{Si}(100)$ substrates at various sputter powers: (a) sample $\mathrm{X} 01$; (b) sample $\mathrm{X} 02$; see text for details.

significantly lower." Comparison with SEM micrographs of other layers reveals that those grown on steam-oxidized silicon wafers exhibit the same structure as $\mathrm{ZnO}$ grown in $\mathrm{Si}(100)$.

We can conclude that $\mathrm{ZnO}$ film growth on crystalline substrates of silicon or $\mathrm{SiO}_{2}$, starts with a bottom layer of small grains, a few hundredths of a micron wide. As thickness increases, taperwise grain growth occurs if the surface temperature is 
high enough (high sputter power) to induce coalescence. This taperwise growth is not explained by the "survival of the fastest" model, since layers are highly oriented from the very first stage as observed by XRD. The thermodynamically driven coalescence mechanism suggested by Lodder et al.$^{19}$ provides a plausible explanation. Dense and "single-crystal-like" films are grown, probably (001) oriented. High oxygen pressure yields more porous layers, while low pressure induces columnar growth.

Amorphous substrates of metals or chemically vapour deposited $\mathrm{SiO}_{2}$ induce a growth of broad columns extending through the film thickness, probably $(00 \overline{1})$ oriented.

\subsection{Surface profiles}

Surface profiles of layers of $1 \mu \mathrm{m} \mathrm{s}-\mathrm{ZnO}$ on silicon all reveal smooth surfaces with a roughness of $1-4 \mathrm{~nm}$. The surface roughness of the $4-5 \mu \mathrm{m} \mathrm{s}-\mathrm{ZnO}$ on chemically vapour deposited $\mathrm{SiO}_{2}$ layers is somewhat higher, i.e. 6-7 nm. Also, slightly etched surface profiles were scanned. Results are summarized in Table IV

TABLE IV

RESULTS OF SURFACE PROFILING ( $50 \mu \mathrm{m}$ SCANS)

\begin{tabular}{|c|c|c|c|c|c|}
\hline \multirow[t]{2}{*}{ Sample } & \multirow[t]{2}{*}{$\begin{array}{l}\text { Substrate } \\
\text { type }\end{array}$} & \multirow[t]{2}{*}{$\begin{array}{l}\text { Oxygen } \\
\text { pressure } \\
(\mathrm{Pa})\end{array}$} & \multirow[t]{2}{*}{$\begin{array}{l}\text { Thickness } \\
\text { of film } \\
(\mu \mathrm{m})\end{array}$} & \multicolumn{2}{|l|}{$\begin{array}{l}\text { Surface } \\
\text { roughness } \\
\text { (nm) }\end{array}$} \\
\hline & & & & $\begin{array}{l}\text { As } \\
\text { deposited }\end{array}$ & $\begin{array}{l}\text { Slightly } \\
\text { etched }\end{array}$ \\
\hline F41 & $\mathrm{Si}(100)$ & 0.59 & 1.1 & 2 & 15 \\
\hline F43 & & 0.92 & 1.0 & 3 & 5 \\
\hline F42 & & 2.1 & 1.0 & 4 & 3 \\
\hline F45 & & 3.9 & 0.8 & 3 & 5 \\
\hline F44 & & 23 & 1.0 & 1 & 2 \\
\hline B65 & Chemically & 0.86 & 4.8 & 6 & 20 \\
\hline B 77 & $\begin{array}{l}\text { vapour } \\
\text { deposited } \\
\mathrm{SiO}_{2}\end{array}$ & & 4.0 & 7 & 30 \\
\hline
\end{tabular}

and are in accordance with SEM observations. The lateral resolution of the surface profiler is too low for the grain width at the surface to be determined.

We can conclude that all layers scanned are smooth. The surface roughness of films grown on chemically vapour deposited $\mathrm{SiO}_{2}$ is somewhat higher than for those deposited on silicon substrates.

\subsection{Auger electron spectroscopy results}

AES was performed on samples $\mathrm{K} 11(1 \mu \mathrm{m} \mathrm{s}-\mathrm{ZnO}$ on silicon) and $\mathrm{B} 77$ ( $4 \mu \mathrm{m}$ $\mathrm{s}-\mathrm{ZnO}$ on chemically vapour deposited $\mathrm{SiO}_{2}$ ) (Fig. 10). Surveys indicate that the 


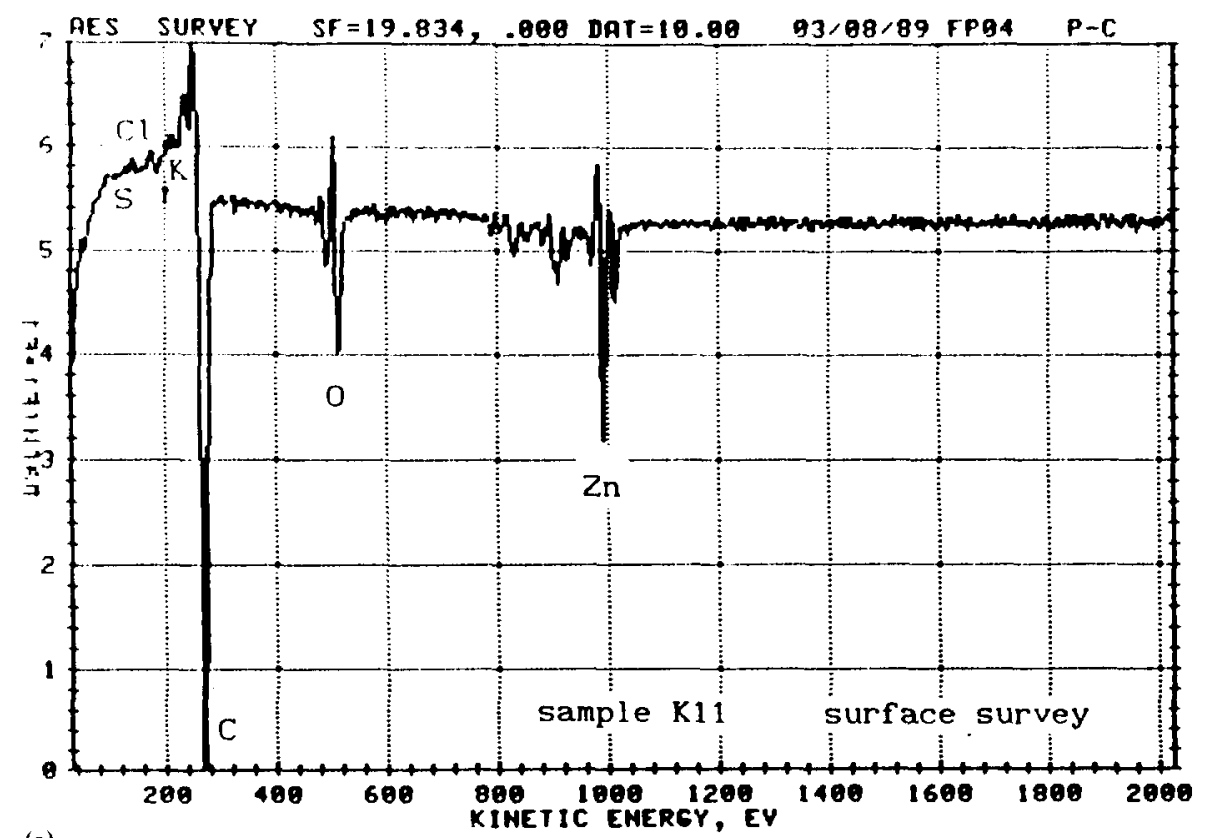

(a)

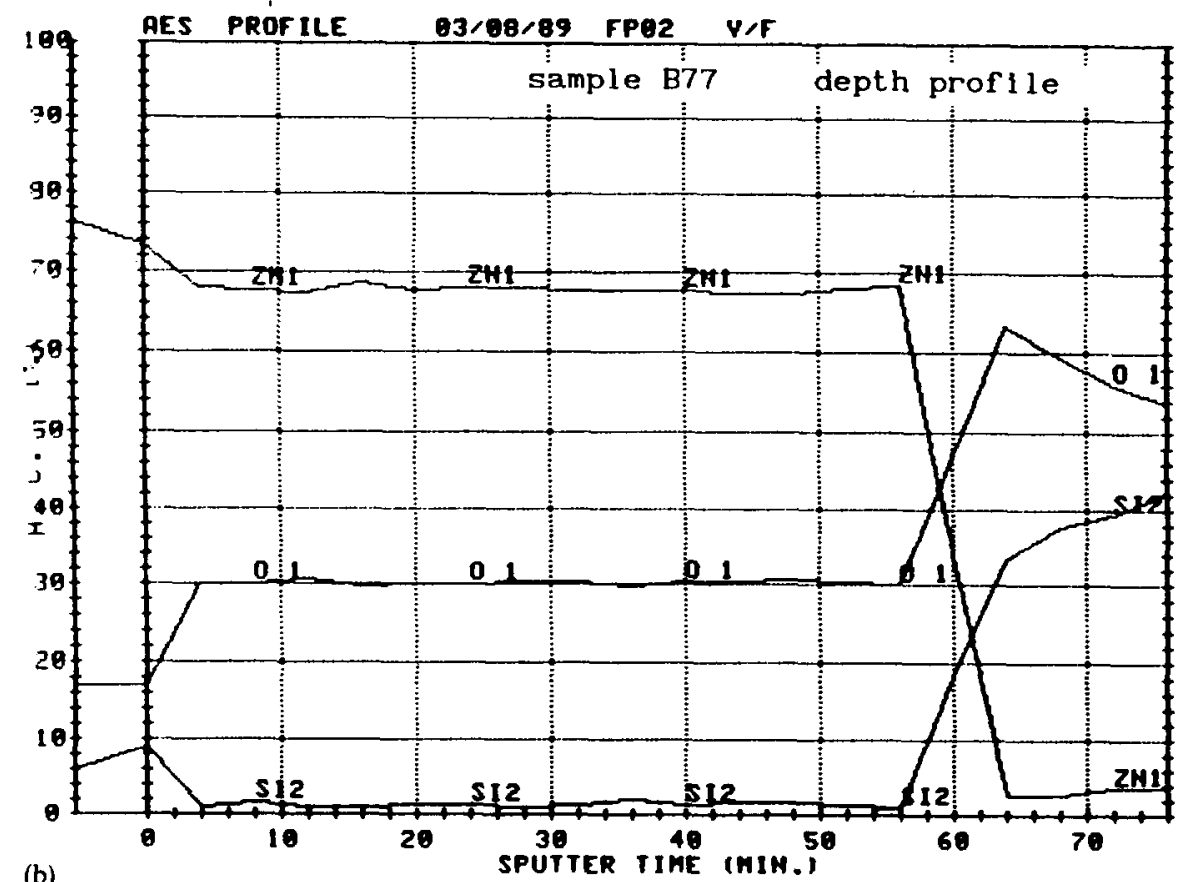

Fig. 10. (a) AES surface survey (sample K11) and (b) depth profile (sample B77) for a ZnO film. 
layers are "Auger clean" (i.e. no impurities present in amounts exceeding \pm 1 at.\%) except for some chlorine and potassium and a large amount of carbon on the surface. Depth profiles show the $\mathrm{Zn}-\mathrm{O}$ ratio to be constant over the film thickness. The $\mathrm{Zn}-\mathrm{O}$ ratio cannot be determined accurately because of possible preferential etching and, moreover, since the Auger electron yield is not known except for elemental zinc and oxygen. For more accurate measurement of impurities and the $\mathrm{Zn}-\mathrm{O}$ ratio, other analytical methods would be required, for instance secondary ion mass spectrometry or Rutherford backscattering.

$\mathrm{Zn}-\mathrm{O}$ ratios as low as 0.6 have been reported for layers sputtered at low substrate temperature ${ }^{24}$. This large "overstoichiometry" is caused by adsorbed oxygen, which is readily desorbed at elevated temperatures (Part II). Since our layers are grown at high substrate temperature $\left(400-450^{\circ} \mathrm{C}\right)$, we expect them to exhibit equilibrium bulk-stoichiometry, which corresponds ${ }^{25}$ to a $\mathrm{Zn}-\mathrm{O}$ ratio of 1 within 1 $\mathrm{ppm}$ for temperatures up to $500^{\circ} \mathrm{C}$. Comparison with Auger spectra from the literature ${ }^{24}$ reveals that the $\mathrm{Zn}-\mathrm{O}$ ratio for our films is approximately 1 , as expected.

We can conclude that the $\mathrm{s}-\mathrm{ZnO}$ layers studied with AES are "Auger clean" and the $\mathrm{Zn}-\mathrm{O}$ ratio is constant over the film thickness and equals approximately 1 .

\subsection{Comparison with Thornton's model}

The Thornton structure zone model for metals sputtered in an argon atmosphere, as described in Section 2, cannot be applied straightforwardly to our sputtered $\mathrm{ZnO}$ films for a number of reasons. First, our $\mathrm{ZnO}$ is reactively sputtered in an oxygen atmosphere and, secondly, $\mathrm{ZnO}$ (with a melting-sublimation point of $2250 \mathrm{~K}$ ) is not a metal. Also, growth rate and sputtering power are not accounted for explicitly in the model. The most uncertain parameter is temperature, since the actual temperature at the surface, where growth occurs, might be some hundreds of kelvins higher than the substrate temperature. Moreover, we have to be aware that the influence of the substrate type, which greatly effects initial growth, is not dealt with in the model. Therefore we regard the Thornton model to be more suited for actual growth where initial layer effects are less important. Nevertheless, general ideas about surface and bulk diffusion and their influence on growth and structure are still valid.

If we take $1400 \mathrm{~K}$ for the melting point, instead of $2250 \mathrm{~K}$, then the observed structures of the $1 \mu \mathrm{m} \mathrm{ZnO} \mathrm{layers} \mathrm{on} \mathrm{silicon} \mathrm{fit} \mathrm{the} \mathrm{Thornton} \mathrm{model} \mathrm{(Fig.} \mathrm{11).} \mathrm{Most} \mathrm{of}$ the layers exhibit a transition zone $T$ structure with a dense, smooth surface and small grains, and are essentially the same (Fig. 5). The grain dimensions increase with temperature (Table III). At high pressures, the layers become porous (zone 1; Fig. 6) and, at low pressures, columnar growth is observed and the layers are rougher (zone 2; Fig. 6, Table IV). However, for layers grown on amorphous substrates, a zone 2 structure is observed, with columns a few tenths of a micron in diameter, extending through the film thickness.

We can conclude that trends in morphology, density and grain size are in agreement with Thornton's model. However, the substrate type, which to a great extent determines the structure of our sputtered $\mathrm{ZnO}$ films, is not accounted for in this model. The same holds for growth rate and sputter power, which greatly influence actual temperature and diffusion at the surface during deposition. 


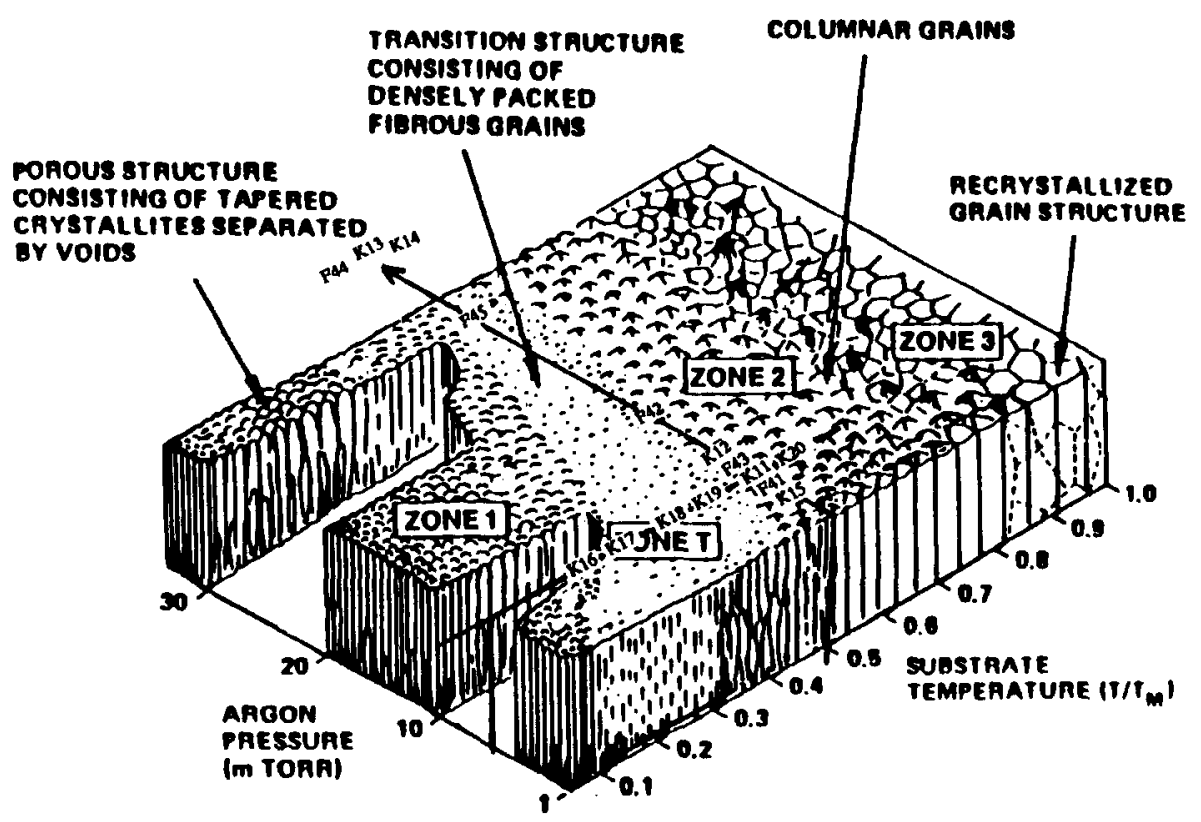

Fig. 11. Samples of sputtered $\mathrm{ZnO}$ films on $\mathrm{Si}(100)$ substrates fit Thornton's structure zone model ${ }^{14}$ (melting temperature of $\mathrm{ZnO}, 2248 \mathrm{~K}$; "fit" temperature, $1400 \mathrm{~K}$ ).

\section{CONCLUSIONS}

In this paper (Part I) the structural and chemical properties of r.f.-sputtered $\mathrm{ZnO}$ films are described. We found that the structural properties depended strongly on the substrate type. All films are polycrystalline $\mathrm{ZnO}$. The individual grains are highly oriented with their crystallographic $c$ axis perpendicular to the substrate from the very first stage of growth, in agreement with Bauer's general texture mode ${ }^{16}$.

Crystalline surfaces of $\mathrm{Si}(100)$ or steam-oxidized $\mathrm{Si}(100)$ induce growth of small grains (a few hundredths of a micron wide and long), probably (001) oriented. These small grains tend to coalesce, depending on temperature, resulting in tapered grains up to $1 \mu \mathrm{m}$ or more in diameter. Lodder et al. ${ }^{19}$ suggested a plausible explanation for this coalescence phenomenon. Amorphous substrates of metals or chemically vapour deposited $\mathrm{SiO}_{2}$ induce growth of broad (a few tenths of a micron wide) columns extending through the film thickness, probably $(00 \overline{1})$ oriented.

Trends in density and grain size are in agreement with Thornton's structure zone model ${ }^{14}$. However, this model cannot be applied straightforwardly to our $\mathrm{ZnO}$ films. It is more suited for actual growth, since the substrate parameters are not accounted for in this model. In addition, growth rate and sputter power, which greatly influence actual temperature and diffusion at the surface during deposition, are not accounted for.

Layers grown under s-conditions (see Section 3) are "Auger clean" and have a $\mathrm{Zn}-\mathrm{O}$ ratio of approximately 1 , constant over the film thickness. 


\section{ACKNOWLEDGMENTS}

The authors would like to thank K. van Goor, M. C. Elwenspoek and J. Baxter (University of Twente) for their help and contributions, and J. J. Kelly and A. R. de Wit (University of Utrecht, The Netherlands) for fruitful discussions and for providing us with the SEM micrograph shown in Fig. 8.

\section{REFERENCES}

1 W. H. G. Horsthuis, Thin Solid Films, 137 (1986) 185.

2 J. G. Smits, H. A. C. Tilmans, K. Hoen, H. Mulder, J. van Vuuren and G. Boom, Sens. Actuators, 4 (1983) 565.

3 S. Bouwstra, University of Twente, personal communication, 1986.

4 F. R. Blom, S. Bouwstra, J. H. J. Fluitman and M. Elwenspoek, Sens. Actuators, 17 (1989) 513.

5 W. Hirschwald, in E. Kaldis (ed.), Current Topics in Materials Science, Vol. 7, North-Holland, Amsterdam, 1981, p. 143.

6 S. Maniv, Vacuum, 33 (1983) 215.

7 T. Shiosaki and A. Kawabata, Ferroelectrics, 42 (1982) 219.

8 F. R. Blom, D. J. Yntema, F. C. M. van de Pol, M. Elwenspoek, J. H. J. Fluitman and Th. J. A. Popma, Sens. Actuators A, 21-23 (1989) 226.

9 S. Sen, D. J. Leary and C. L. Bauer, Thin Solid Films, 94 (1982) 7.

10 S. B. Krupanidhi and M. Sayer, J. Appl. Phys., 56 (1984) 3308.

11 K. L. Chopra, Thin Film Phenomena, McGraw-Hill, New York, 1969.

12 J. L. Vossen and W. Kern, Thin Film Processes, Academic Press, New York, 1978.

13 B. A. Movchan and A. V. Demchishin, Phys. Met. Metallogr., 28 (1969) 83 (English translation).

14 J. A. Thornton, J. Vac. Sci. Technol, /l (1974) 666.

15 J. A. Thornton, Annu. Rev. Mater. Sci., 7 (1977) 239.

16 E. Bauer, in G. H. Bancroft (ed.), Trans. 9th Vacuum Symp. of the American Vacuum Society, 1962, Macmillan, New York, 1962, p. 35.

17 E. Bauer, in M. H. Francombe and H. Sata (eds.), Single Crystal Films, Pergamon, Oxford, 1964, pp. 43-67.

18 A. Van der Drift, Philips Res. Rep., 22 (1967) 267.

19 J. C. Lodder, T. Wielinga and J. Worst, Thin Solid Films, 101 (1983) 61.

20 Joint Committee on Powder Diffraction Standards, Powder Diffraction File (International Center for Powder Diffraction Data, Swarthmore, PA).

21 A. Guinier, X-ray Crystallographic Technology, Hilger and Watts, London, 1959.

22 F. S. Hickernell, IEEE Trans. Son. Ultrason., 32 (1985) 621.

23 A. R. de Wit, M. D. Jansen and J. J. Kelly, Appl. Surf. Sci., 45 (1990) 21.

24 Y. Shapira, S. M. Cox and D. Lichtman, Surf. Sci, 50 (1975) 503.

25 K. Teske, H. Oppermann and G. Stöver, Z. Anorg. Allg. Chem., 511 (1984) 72. 